\title{
Emergência e crescimento inicial de plântulas de Platymiscium floribundum Vog. em função de diferentes posições e profundidades de semeadura
}

\author{
Emergence and initial growth of Platymiscium florinbundum Vog. in function \\ of different positions and sowing depths
}

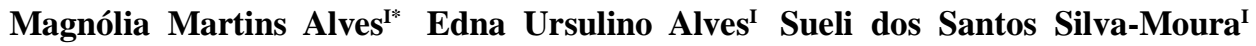 \\ Luciana Rodrigues de Araújo ${ }^{I}$ Rosemere dos Santos Silva ${ }^{I}$ Marina Matias Ursulino ${ }^{I}$
}

RESUMO

Platymiscium floribundum Vog., pertencente à família Fabaceae, pode ser utilizada no paisagismo, em reflorestamentos e na recomposição de áreas degradadas e de preservação permanente. Objetivou-se verificar o efeito da posição da semente e da profundidade de semeadura na emergência $e$ crescimento inicial de plântulas de $\boldsymbol{P}$. floribundum. O experimento foi realizado em delineamento inteiramente ao acaso, utilizando-se diferentes posições das sementes no substrato areia: hilo voltado para baixo $(H B)$, hilo voltado para o lado, formando um ângulo de $90^{\circ}$ em relação ao eixo imaginário com o substrato $(H L)$ e hilo voltado para cima $(\mathrm{HC})$, nas profundidades de semeadura de 0 , 1, 2, 3, 4, 5 e $6 \mathrm{~cm}$. Avaliou-se a porcentagem, primeira contagem $e$ índice de velocidade de emergência de plântulas, assim como o comprimento e massa seca das plântulas normais. Para o teste de emergência de plântulas de P. floribundum, a semeadura deve ser na profundidade de até 2,0cm com o hilo voltado para baixo.

Palavras-chave: Sacambu, sementes florestais, tecnologia de sementes.

\section{ABSTRACT}

Platymiscium floribundum Vog. belonging to the Fabaceae family is an ornamental tree that can be used in landscaping, reforestation, restoration of degraded areas and permanent preservation. Thus it aimed at verifying the effect of seed position and sowing depth on emergence and initial growth of $\boldsymbol{P}$. floribundum seedlings. The experiment was performed in a completely randomized design using different seeds positions in the substrate sand: hilum facing down (HD), hilum facing side, forming an angle of $90^{\circ}$ with respect to the imaginary axis with substrate (HS) and hilum facing upwards (HU) in the sowing depth of $0,1,2,3,4,5$ and $6 \mathrm{~cm}$. It evaluated the percentage, the first count and emergence speed index, as well as length and dry mass of seedlings. To test the emergence of $\boldsymbol{P}$. floribundum sowing should be at a depth of $2.0 \mathrm{~cm}$ with the hilum facing down.

Key words: Sacambu, forest seeds, vigor, seed technology.

\section{INTRODUÇÃO}

Platymiscium floribundum Vog.,
pertencente à família Fabaceae, conhecida popularmente por sacambu, jacarandá-do-litoral, jacarandá-rosa e jacarandá-vermelho, é uma planta característica da floresta pluvial da encosta atlântica. A espécie é esciófita e seletiva higrófita, com desenvolvimento lento no campo, pois habita quase que exclusivamente o interior da floresta primária densa, nas planícies aluviais, várzeas úmidas e início de encostas e possui grande potencial para exploração econômica, podendo ser utilizada tanto como produtora de madeira para imobiliário, como planta ornamental, devido à intensa floração com coloração amarelo-alaranjado. Pode ser também empregada em reflorestamentos mistos, destinados à recomposição de áreas degradadas e de preservação permanente (LORENZI, 2002).

O insucesso na emergência da plântula e no estabelecimento inicial da muda no campo, para fins de reflorestamento, pode ser devido a fatores como contato da semente com o solo, deslocamento do ponto de semeadura, semeadura muito profunda, excesso ou escassez de umidade e perdas de sementes e plântulas pela ação de insetos e aves (DOUGHERTY, 1990). Dessa forma, a rapidez e uniformidade da germinação são características desejáveis na formação de mudas, pois quanto maior o período que a plântula permanece nos estádios iniciais de desenvolvimento mais tempo fica sujeita às condições adversas do ambiente (MARTINS et al., 1999).

\footnotetext{
'Departamento de Fitotecnia e Ciências Ambientais (DFCA), Centro de Ciências Agrárias (CCA), Universidade Federal da Paraíba (UFPB), 58397-000, Areia, PB, Brasil. E-mail: magecologia@ @otmail.com.*Autor para correspondência. Recebido 15.06.12 Aprovado 13.05.14 Devolvido pelo autor 18.08.14 CR-2012-0406.R2
} 
A semeadura não deve ser muito profunda, pois o peso do material sobre a semente constitui um fator físico inibidor da emergência de plântulas, especialmente daquelas menos vigorosas, enquanto as semeaduras muito superficiais predispõem as sementes a qualquer variação ambiental, como excesso ou déficit hídrico ou térmico, as quais podem dar origem às plântulas pequenas e menos vigorosas (TILLMANN et al., 1994). Nesse sentido, JELLER \& PEREZ (1997) enfatizaram que semeaduras rasas podem facilitar o ataque de predadores, danos decorrentes da irrigação ou, ainda, expor e destruir a raiz primária, de forma que a profundidade ideal de semeadura é aquela que garante uma germinação homogênea das sementes, rápida emergência das plântulas e produção de mudas vigorosas.

Da mesma maneira, também há posições de semeadura que são melhores para a germinação, a emergência e o desenvolvimento das plântulas (MARTINS \& CARVALHO, 1993), uma vez que a posição da semente também pode favorecer positivamente a germinação, como foi observado em Cedrela fissilis L. (SANTOS et al., 2009) e Amburana cearensis (Allemão) A.C. Smith (GUEDES et al., 2010). No entanto, a posição da semente pode não influenciar no processo germinativo, como se verificou na emergência de plântulas de Oenocarpus mapora Karsten (NASCIMENTO et al., 2002) e Moringa oleifera Lam. (SOUSA et al., 2007).

Assim, em qualquer cultivo, a profundidade e a posição de semeadura devem ser adequadas para garantir a germinação das sementes, a emergência e o desenvolvimento das plântulas, pois a posição correta proporciona germinação rápida e uniforme, tornando as plântulas menos vulneráveis às condições adversas do meio, por emergirem mais rápido no solo e passarem menos tempo nos estágios iniciais de desenvolvimento (MARTINS et al., 1999).

Diante do exposto, objetivou-se determinar a posição e a profundidade de semeadura mais adequada para a emergência e crescimento inicial de plântulas de $\boldsymbol{P}$. floribundum Vog.

\section{MATERIAL E MÉTODOS}

O trabalho foi conduzido no Laboratório de Análise de Sementes do Departamento de Fitotecnia e Ciências Ambientais do Centro de Ciências Agrárias da Universidade Federal da Paraíba, no município de Areia - PB, situado a $575 \mathrm{~m}$ de altitude, $6^{\circ} 58^{\prime}$ de latitude Sul e $35^{\circ} 41^{\prime}$ de longitude Oeste de Greenwich. O clima da região, segundo classificação de Köppen, é do tipo As', que se caracteriza por ser quente $\left(25^{\circ} \mathrm{C}\right)$ e úmido $(85 \%)$, com chuvas de outonoinverno $(1.200 \mathrm{~mm}$ anuais) e período de estiagem de 5 a 6 meses, com solos moderadamente ácidos (GONDIM \& FERNANDES, 1980).

As sementes de $\boldsymbol{P}$. floribundum foram obtidas de frutos em início do processo de deiscência natural, colhidos de dez matrizes localizadas na zona rural no mesmo município, os quais foram levados para o Laboratório de Análise de Sementes e mantidos à sombra para secagem natural durante oito dias; em seguida os frutos foram abertos manualmente com auxílio de tesoura para a retirada das sementes. As sementes da espécie em estudo, em resultados preliminares, apresentaram uma porcentagem de germinação de $76 \%$, quando submetidas à temperatura de $20-30^{\circ} \mathrm{C}$, alternada com o volume de água de duas vezes a massa do substrato seco. Após o beneficiamento, as sementes foram submetidas à determinação do teor de água e testes descritos a seguir.

Teor de água - determinado pelo método padrão da estufa a $105 \pm 3^{\circ} \mathrm{C}$ durante 24 horas, conforme prescrições das Regras para Análise de Sementes (BRASIL, 2009), com modificação no número de sementes e de repetições, que foram quatro amostras de 10 sementes, sendo os resultados expressos em porcentagem.

Teste de emergência de plântulas - as sementes foram semeadas em bandejas plásticas (49 $33 \times 7 \mathrm{~cm}$ de comprimento, largura e profundidade, respectivamente), contendo areia lavada e esterilizada em autoclave à temperatura de $120^{\circ} \mathrm{C}$, durante duas horas, em diferentes posições, tendo como referência o hilo: sementes com o hilo voltado para baixo (HB); sementes com o hilo de lado, formando um ângulo de $90^{\circ}$ em relação ao eixo imaginário (HL) e sementes com o hilo voltado para cima (HC), nas profundidades de $0,1,2,3,4,5$ e $6 \mathrm{~cm}$. As avaliações do número de plântulas emergidas foram realizadas diariamente, no mesmo horário, sendo o teste conduzido em casa de crescimento, com cobertura de plástico, valores médios de temperatura de $33^{\circ} \mathrm{C}$ e umidade relativa do ar de $70 \%$, durante 21 dias, com irrigações diárias até se verificar o início da drenagem natural.

Índice de velocidade de emergência (IVE) - o índice de velocidade de emergência (IVE) foi determinado mediante contagens diárias do número de plântulas emersas durante 21 dias e o cálculo foi de acordo com a fórmula proposta por MAGUIRE (1962).

Primeira contagem de emergência - a primeira contagem foi realizada juntamente com o teste de emergência, a qual consistiu na porcentagem 
de plântulas emergidas aos 8 dias após a semeadura, levando-se em consideração e emergência do epicótilo.

Comprimento e massa seca plântulas após a contagem final do teste de emergência, as plântulas normais foram submetidas a medições, da raiz ao ápice caulinar e, em seguida, separaram-se as raízes e parte aérea, as quais foram postas para secar em estufa regulada a $65^{\circ} \mathrm{C}$ até peso constante (48 horas) e, decorrido esse período, pesadas em balança de precisão de 0,001g (VIEIRA \& CARVALHO, 1994).

Delineamento experimental e análise estatística - o delineamento experimental foi inteiramente ao acaso, com os tratamentos distribuídos em esquema fatorial $3 \times 6$ (posições e profundidades de semeadura), em quatro repetições de 25 sementes para cada tratamento, cujos dados foram submetidos à análise de variância e de regressão polinomial.

\section{RESULTADOS E DISCUSSÃO}

O teor de água das sementes de $\boldsymbol{P}$. floribundum no momento da realização do experimento encontrava-se em torno de $10 \%$, o qual estava de acordo com as recomendações de CARVALHO \& NAKAGAWA (2012) para a instalação de testes de germinação e vigor, que é de 8 a $10 \%$

A porcentagem de emergência de plântulas decresceu com o aumento da profundidade de semeadura (Figura 1A), independentemente da posição em que foram semeadas; para a semeadura com o hilo para o lado (HL), foram constatados $52 \%$ de plântulas emergidas, na profundidade de $0,52 \mathrm{~cm}$; para aquelas cujo hilo ficou direcionado para baixo, houve um decréscimo linear na porcentagem de emergência com o aumento da profundidade de semeadura e, quando a semeadura foi realizada com o hilo para cima, também se constataram reduções na porcentagem de emergência com o aumento na profundidade de semeadura. Com relação às posições, o melhor desempenho das sementes foi quando a semeadura foi realizada com hilo direcionado para o lado (HL) em todas as profundidades.

Essa redução na porcentagem de emergência deve estar relacionada com o aumento da barreira física proporcionado pelas maiores profundidades, que, segundo SILVA et al. (2007), constitui-se em obstáculo que as sementes terão que superar e com isso consumem maior quantidade de reservas. De forma semelhante, PEREZ et al. (1999) relataram que houve redução na porcentagem e velocidade de emergência de plântulas de Peltophorum dubium (Spreng.) Taub., à medida que se aumentou a profundidade de semeadura.

A posição e a profundidade de semeadura influenciaram a emergência de plântulas de algumas espécies, a exemplo das sementes de Erythrina velutina Willd., que, quando semeadas com o hilo para baixo, expressaram a emergência máxima (99\%), na profundidade de $1,82 \mathrm{~cm}$; para aquelas cujo hilo ficou direcionado para cima, o maior porcentual de emergência $(63 \%)$ foi na profundidade de $1,47 \mathrm{~cm}$, enquanto que, na profundidade $2,04 \mathrm{~cm}$, verificou-se maior porcentagem de emergência (89\%) para as sementes com o hilo para o lado (CARDOSO et al., 2008).

De forma semelhante, para Cedrela fissilis L., a profundidade de $2,2 \mathrm{~cm}$ proporcionou às plântulas melhor resposta para a porcentagem de emergência (67\%) quando as sementes foram semeadas com o hilo voltado para baixo, enquanto, nas sementes com hilo para o lado, foram obtidos $32 \%$ de plântulas emergidas na profundidade de $2,18 \mathrm{~cm}$ (SANTOS et al., 2009). As sementes de Amburana cearensis (Allemão) A.C. Smith devem ser semeadas na profundidade de $3,5 \mathrm{~cm}$ para emergência adequada das plântulas (GUEDES et al., 2010), enquanto a posição da semente não influenciou a emergência de plântulas de Moringa oleifera Lam. (SOUSA et al., 2007).

Em relação à porcentagem (Figura 1B) e índice de velocidade de emergência de plântulas (Figura 1C) de $\boldsymbol{P}$. floribundum, constatou-se diminuição significativa nos seus valores, à medida que foi aumentando a profundidade em todas as posições (hilo voltado para baixo, para cima e para o lado). Em se tratando das posições, a melhor uniformidade de emergência (primeira contagem e velocidade de emergência) foi alcançada quando a semeadura foi realizada com hilo direcionado para baixo (HB) em todas as profundidades.

Diante dos resultados, concorda-se com MARTINS et al. (1999) quando relataram que a semeadura na posição correta proporciona germinação rápida e uniforme, pois SANTOS et al. (2009) enfatizaram que, em profundidades maiores, existe maior concentração de $\mathrm{CO}_{2}$, acarretando, assim, efeito fitotóxico e, consequentemente, afetando a porcentagem e velocidade de emergência.

Resultados semelhantes foram obtidos com Erythrina velutina Willd. (CARDOSO et al., 2008) e Zizyphus joazeiro Mart., cujos valores na primeira contagem, bem como a velocidade de emergência, reduziram com o aumento na profundidade de

Ciência Rural, v.44, n.12, dez, 2014. 

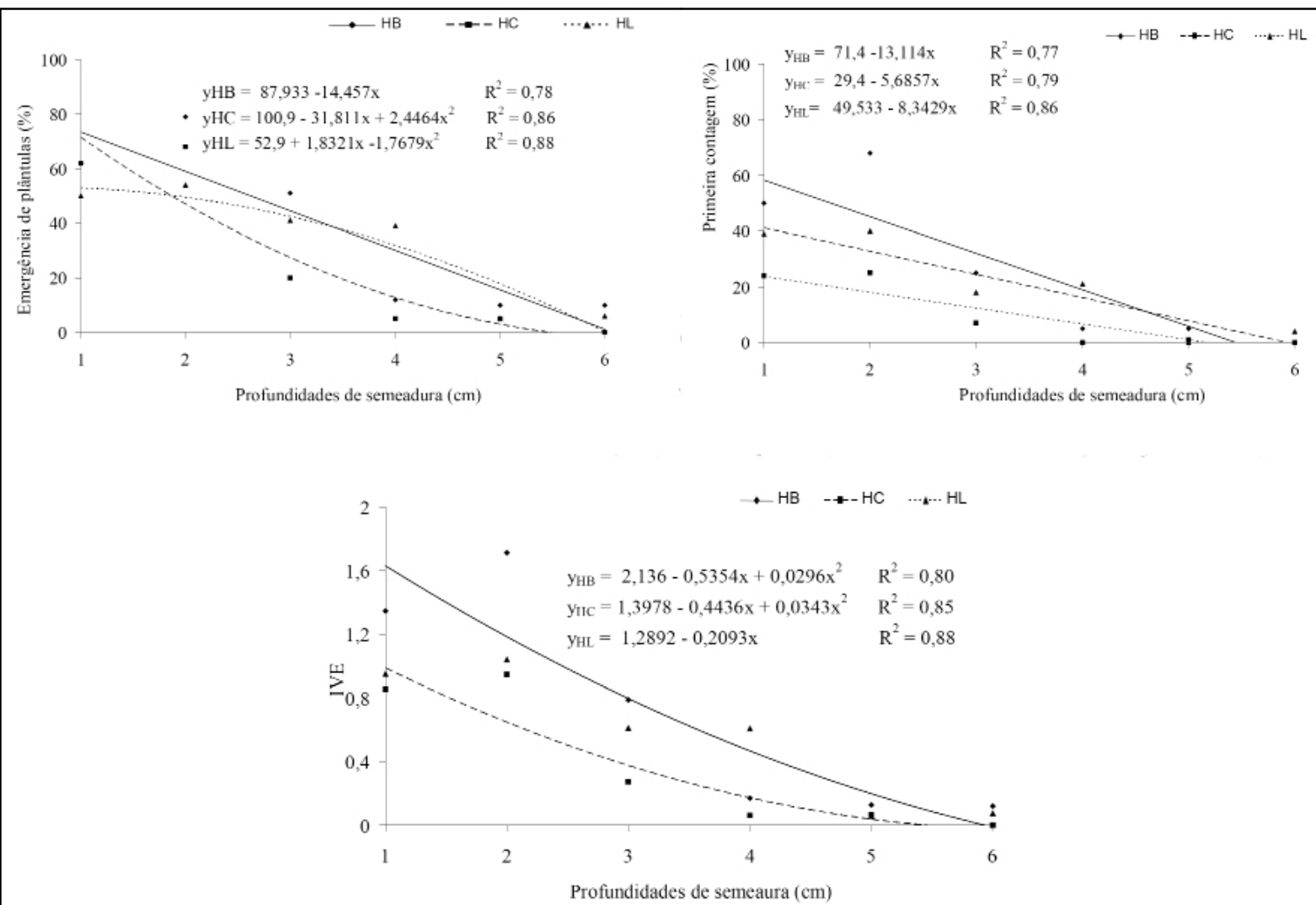

Figura 1 - Emergência (A), primeira contagem (B) e índice de velocidade de emergência IVE (C) de plântulas de $\boldsymbol{P}$. floribundum em função de diferentes posições e profundidades de semeadura.

HB - hilo para o baixo; HC - hilo para cima; HL - hilo para o lado.

semeadura (ALVES et al., 2008). Para Cedrela fissilis L., a velocidade máxima de emergência de plântulas ocorreu quando a semeadura foi até $2,17 \mathrm{~cm}$ de profundidade com as sementes postas para germinar com o hilo para baixo (SANTOS et al., 2009), enquanto, para Amburana cearensis (Allemão), A.C. Smith GUEDES et al. (2010) observaram que, na semeadura com o hilo voltado para baixo, houve maior velocidade de emergência de plântulas na profundidade de $3,5 \mathrm{~cm}$.

O comprimento da raiz primária das plântulas $\boldsymbol{P}$. floribundum decresceu linearmente com o aumento da profundidade, independentemente da posição de semeadura. No entanto, quando as sementes foram semeadas com o hilo para o lado (HL), na profundidade de $4 \mathrm{~cm}$, e com o hilo para baixo (HB) a $5 \mathrm{~cm}$ originaram plântulas com raízes mais compridas, provavelmente, devido a um gasto maior de energia durante a fase de emergência, o que prejudicou o desenvolvimento normal das plântulas oriundas dessas sementes (Figura 2A).
Pelos resultados do comprimento das plântulas de Zizyphus joazeiro Mart. obtidos por ALVES et al. (2008), constatou-se que houve uma redução em função do aumento na profundidade de semeadura, enquanto as sementes de Erythrina velutina Willd. (CARDOSO et al., 2008) e Cedrela fissilis L. (SANTOS et al., 2009) originaram plântulas com o maior comprimento na profundidade de $2,36 \mathrm{~cm}$, postas para germinar com o hilo voltado para o lado. O maior comprimento de plântulas de Amburana cearensis (Allemão) A.C. Smith foi obtido com sementes distribuídas com o hilo de lado na profundidade de $3,4 \mathrm{~cm}$ (GUEDES et al., 2010). Em contrapartida, as diferentes posições de semeadura (semente com ápice para cima, para o lado e para baixo) não influenciaram no comprimento da raiz primária de plântulas de Moringa oleifera Lam. (SOUSA et al., 2007).

Quanto ao comprimento da parte aérea (Figura 2B), observa-se que, quando as sementes de $\boldsymbol{P}$. floribundum foram distribuídas com o hilo 


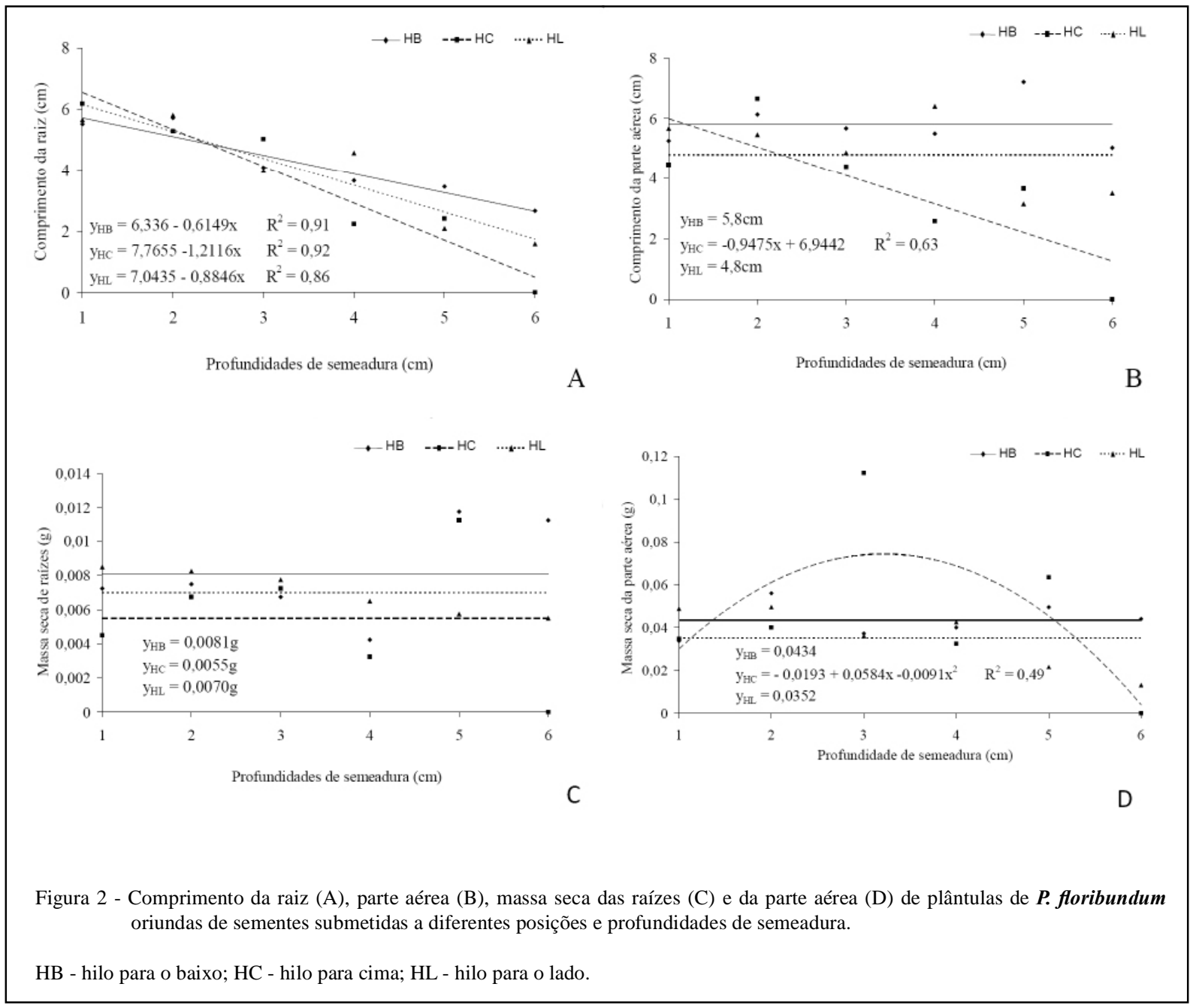

voltado para cima (HC), ocorreu decréscimo linear, à medida que a semeadura foi mais profunda, enquanto que, com o hilo para baixo (HB) e de lado (HL), não houve ajuste dos dados a modelos de regressão, cujo comprimento médio foi de 5,8 e $4,8 \mathrm{~cm}$, respectivamente. Ao se comparar a influência das posições, verifica-se que os menores comprimentos de parte aérea foram obtidos de sementes como o hilo para cima (HC) nas profundidades de 4 a $6 \mathrm{~cm}$ e com o hilo para o lado (HL) entre 5 e $6 \mathrm{~cm}$. Em semeaduras mais superficiais, normalmente, as sementes ficam sujeitas às variações ambientais, podendo originar plântulas pequenas e fracas (TILLMANN et al., 1994). A parte aérea das plântulas de Oenocarpus mapora Karsten, oriundas das unidades de dispersão semeadas com a rafe na horizontal e para baixo, foi prejudicada, obtendo-se os menores comprimentos (NASCIMENTO et al., 2002).

Os dados de massa seca das raízes de plântulas de $\boldsymbol{P}$. floribundum (Figura 2C) originadas de sementes postas para germinar com hilo voltado para baixo (HB) e para cima (HC) não se ajustaram a modelos de regressão. Sendo os valores médios de 0,008 e $0,005 \mathrm{~g}$, respectivamente, para as sementes semeadas com o hilo para cima (HC), os dados da massa seca das raízes também não se ajustaram a modelos de regressão, cujo conteúdo médio foi de $0,007 \mathrm{~g}$. De forma semelhante, não houve diferença estatística entre as diferentes posições de semeadura.

De forma diferente ao que se verificou na presente pesquisa, a massa seca das raízes de plântulas de Inga ingoides (Rich.) Willd., oriundas de sementes semeadas com o hilo para o lado e para baixo, reduziu significativamente, à medida que foi aumentando a profundidade da semeadura (LAIME et al., 2010). Para as plântulas de Erythrina velutina Willd., oriundas de sementes com o hilo para baixo, verificou-se maior conteúdo de massa seca da parte aérea, na profundidade de $0,50 \mathrm{~cm}$. Aquelas cujo hilo ficou direcionado para cima expressaram maior 
conteúdo de massa seca da parte aérea na profundidade de $1,67 \mathrm{~cm}$, enquanto, na profundidade $1,24 \mathrm{~cm}$, foi verificado o maior conteúdo de massa seca da parte aérea das plântulas originadas de sementes posicionadas com hilo para o lado (CARDOSO et al., 2008).

Como relação à massa seca da parte aérea das plântulas de P. floribundum (Figura 2D), quando as sementes foram semeadas com hilo voltado para cima (HC), houve um aumento do conteúdo de massa seca das plântulas, à medida que foi aumentando a profundidade da semeadura, cujo maior conteúdo $(0,96 \mathrm{~g})$ ocorreu na profundidade $3,2 \mathrm{~cm}$. Quando as sementes foram semeadas com hilo voltado para baixo (HB) e de lado (HL), os dados não se ajustaram a modelos de regressão, obtendo valores médios de 0,043 e 0,035g, respectivamente. Quando se compararam as posições, os menores valores de massa seca da parte aérea ocorreram em plântulas originadas de sementes posicionadas com o hilo para o lado (HL), nas profundidades de 3,5 e $6 \mathrm{~cm}$, bem como com o hilo para baixo (HB) a $3 \mathrm{~cm}$ e hilo para cima (HC) a $6 \mathrm{~cm}$.

Resultados semelhantes foram obtidos por LAIME et al. (2010), quando verificaram que os dados de massa seca de plântulas de Inga ingoides (Rich.) Willd. oriundas de sementes com o hilo para baixo e para o lado não se ajustam a modelos de regressão. A massa seca da parte aérea das plântulas de Moringa oleifera Lam. não teve relação substancial com a profundidade de semeadura (SOUSA et al., 2007). No entanto, para Zizyphus joazeiro Mart., houve uma redução de $0,015 \mathrm{~g}$ na massa seca das plântulas a cada centímetro de aumento, na profundidade de semeadura (ALVES et al., 2008).

Quando o posicionamento do hilo foi para o lado, o máximo conteúdo de massa seca das plântulas de Amburana cearensis (Allemão) A.C. Smith. ocorreu na profundidade de 3,3cm (GUEDES et al., 2010). A massa seca das plântulas de Cedrela fissilis L., cujas sementes foram postas para germinar com hilo voltado para baixo, chegou ao maior conteúdo na profundidade de $2,35 \mathrm{~cm}$. Aquelas cujo hilo ficou direcionado para o lado expressaram maior conteúdo de massa seca na profundidade de $2,28 \mathrm{~cm}$ (SANTOS et al., 2009).

O maior conteúdo de massa seca da parte aérea das plântulas de Erythrina velutina Willd. foi quando as sementes foram posicionadas com o hilo para baixo na profundidade de $0,50 \mathrm{~cm}$. Aquelas cujo hilo ficou direcionado para cima expressaram maior conteúdo de massa seca da parte aérea na profundidade de $1,67 \mathrm{~cm}$, enquanto, na profundidade $1,24 \mathrm{~cm}$, foi verificado o maior conteúdo de massa seca da parte aérea das plântulas originadas de sementes com hilo para o lado (CARDOSO et al., 2008). No entanto, a massa seca da parte aérea de plântulas de Inga ingoides (Rich.) Willd., oriundas de sementes com o hilo voltado para cima, reduziu à medida que foi aumentanda a profundidade da semeadura (LAIME et al., 2010).

\section{CONCLUSÃO}

Para o teste de emergência de plântulas de P. floribundum, a semeadura deve ser na profundidade de até $2,0 \mathrm{~cm}$ com o hilo voltado para baixo.

\section{REFERÊNCIAS}

ALVES, E.U. et al. Profundidades de semeadura para emergência de plântulas de juazeiro. Ciência Rural, v.38, n.4, p.1158-1161, 2008. Disponível em: 〈http://www.scielo.br/pdf/cr/v38n4/a42v38n4.pdf>. Acesso em: 09 nov. 2012. doi: 101590/S0103-84782008000400042.

BRASIL. Ministério da Agricultura, Pecuária e abastecimento. Regras para análise de sementes. Secretaria de Defesa Agropecuária. Brasília: MAPA/ACS, 2009. 395p.

CARDOSO, E.A. et al. Emergência de plântulas de Erythrina velutina em diferentes posições e profundidades de semeadura. Ciência Rural, v.38, n.9, p.2618-2621, 2008. Disponível em: <http://www.scielo.br/pdf/cr/v38n9/a34v38n9.pdf>. Acesso em: 09 nov. 2012. doi: 10.1590/S0103-84782008000900034.

CARVAlHO, N.M.; NAKAGAWA, J. Sementes: ciência, tecnologia e produção. 5.ed. Jaboticabal: FUNEP, 2012. 590p.

DOUGHERTY, P.M. A field investigation of the factors which control germination and establishment of loblolly pine seeds. Georgia: Forestry Commission, 1990. (Forestry Commission. n.7). p.5.

GONDIM, A.W.A.; FERNADES, B. Probabilidade de chuvas para o município de Areia-PB. Agropecuária Técnica, v.1, n.1, p.5563, 1980 .

GUEDES, R.S. et al. Emergência e vigor de plântulas de Amburana cearensis (Allemão) A.C. Smith em função da posição e da profundidade de semeadura. Semina: Ciências Agrárias, v.31, n.4, p.843-850, 2010. Disponível em: <http://www.uel.br/revistas/ uel/index.php/semagrarias/article/view/7593/6679>. Acesso em: 09 nov. 2012. doi: 10.5433/1679-0359.2010v31n4p843.

JELLER, H.; PEREZ, S.C.J.G.A. Efeito da salinidade e semeadura em diferentes profundidades na viabilidade e no vigor de Copaifera langsdorffii Desf. - Caesalpiniaceae. Revista Brasileira de Sementes, v.19, n.2, p.218-224, 1997. Disponível em: <http://www. abrates.org.br/revista/artigos/1997/v19n2/artigo13.pdf>. Acesso em: 10 nov. 2012. doi: 01002945200700010004000007.

LAIME, E.M.O. et al. Emergência e crescimento inicial de plântulas de Inga ingoides (Rich.) Willd. em função de posições e profundidades de semeadura. Semina: Ciências Agrárias, v.31, n.2, p.361-372, 2010. Disponível em: <http://www.uel.br/revistas/ uel/index.php/semagrarias/article/view/5310/4830>. Acesso em: 10 nov. 2012. doi: 10.5433/1679-0359.2010v31n2p361. 
LORENZI, H. Árvores brasileiras: manual de identificação e cultivo de plantas arbóreas do Brasil. Plantarum: Nova Odessa, 2002. 368p.

MAGUIRE, J.D. Speed of germination aid in selection and evaluation for seedling emergence and vigor. Crop Science, v.2, n.2, p.176-177, 1962.

MARTINS, C.C.; CARVALHO, N.M. Efeito da posição da semente na semeadura sobre a emergência do feijão e da soja. Revista Brasileira de Sementes, v.15, n.1, p.63-65, 1993.

MARTINS, C.C. et al. Efeito da posição da semente no substrato e no crescimento inicial das plântulas de palmito-vermelho (Euterpe espiritusantensis Fernandes Palmae). Revista Brasileira de Sementes, v.21, n.1, p.164-173, 1999. Disponível em: <http://www. abrates.org.br/portal/revista/artigos-publicados>. Acesso em: 15 nov.2012. doi: 01013122200200010002600006 .

NASCIMENTO, W.M.O. et al. Influência da posição de semeadura na germinação, vigor e crescimento de plântulas de bacabinha (Oenocarpus mapora karsten Arecaceae). Revista Brasileira de Sementes, v.24, n.1, p.179-182, 2002. Disponível em: <http:// www.scielo.br/pdf/rbs/v24n1/v24n1a26.pdf >. Acesso em: 13 nov. 2012. doi: 10.1590/S0101-31222002000100026.

PEREZ, S.C.J.G.A. et al. Influência do armazenamento, substrato, envelhecimento precoce e profundidade de semeadura na germinação de canafístula. Bragantia, v.58, n.1, p.5768, 1999. Disponível em: <http://www.scielo.br/pdf/brag/ v58n1/0981.pdf>. Acesso em: 13 nov. 2012. doi: 10.1590/S000687051999000100008 .

SANTOS, S.S. etal. Emergência e vigor de plântulas de Cedrela fissilis L. em função de diferentes posições de profundidades de semeadura. Revista Biotemas, v.22, n.4, p.45-52, 2009. Disponível em: 〈http:// www.biotemas.ufsc.br/volumes/pdf/volume224/45a52.pdf>. Acesso em: 04 dez.2012. doi: 10.5007/2175-7925.2009v22n4p45.

SILVA, B.M.S. et al. Influência da posição e da profundidade de semeadura na emergência de plântulas de açaí (Euterpe oleracea Mart. Arecaceae). Revista Brasileira de Fruticultura, v.29, n.1, p.187-190, 2007. Disponível em: <http://www.scielo.br/pdf/rbf/ v29n1/a40v29n1.pdf>. Acesso em: 04 dez. 2012. doi: 10.1590/ S0100-29452007000100040.

SOUSA, A.H. et al. Profundidades e posições de semeadura na emergência e no desenvolvimento de plântulas de moringa. Revista Caatinga, v.20, n.4, p.56-60, 2007. Disponível em: <http://redalyc.uaemex.mx/redalyc/pdf/2371/237117664009.pdf>. Acesso em: 20 dez. 2012. doi: 2371237117664009.

TILLMANN, M.A.A. et al. Efeito da profundidade de semeadura na emergência de plântulas de tomate. Scientia Agricola, v.52, n.2, p.260-263, 1994. Disponível em: <http://www.scielo.br/pdf/ sa/v51n2/10.pdf>. Acesso em: 20 dez. 2012. doi: 10.1590/S010390161994000200010 .

VIEIRA, R.D.; CARVALHO, N.M. Testes de vigor em sementes. Jaboticabal: FUNEP/UNESP, 1994. 164p. 